\title{
Assessment of Broiler Chicken Welfare in Southern Brazil
}

\section{-Author(s)}

\author{
Federici JF' \\ Vanderhasselt $\mathrm{R}^{\prime \prime}$ \\ Sans ECO' \\ Tuyttens FAM",III \\ Souza APO \\ Molento CFM'
}

Animal Welfare Laboratory, Federal University of Paraná, Curitiba, Paraná, Brazil

" Animal Sciences Unit, Institute for Agricultural and Fisheries Research, Melle, Belgium

III Faculty of Veterinary Medicine, Ghent University, Merelbeke, Belgium

\section{Mail Address}

Corresponding author e-mail address Carla Forte Maiolino Molento

Universidade Federal do Paraná, Departamento de Zootecnia, Rua dos Funcionários, 1540 - CEP 80035-050 Curitiba, Paraná, Brasil.

Phone: (5541) 33505788

Email: carlamolento@ufpr.br

\section{- Keywords}

Animal welfare, assessment, diagnosis, poultry welfare, Welfare Quality ${ }^{\circledR}$.

\section{ABSTRACT}

Scientific literature on broiler chicken welfare in Brazilian industrial systems is scarce. This study aimed at assessing broiler chicken welfare on industrial farms in the State of Rio Grande do Sul, Southern Brazil, using the Welfare Quality ${ }^{\circledR}$ assessment protocol for poultry, to provide directly applicable scientific information. Results are presented as criteria scores ranging from 0 to 100, with higher scores indicating better welfare; and percentages of prevalence. The scores classified as excellent (above 80) were absence of prolonged thirst, absence of prolonged hunger, litter quality, breast blister and touch test. Enhanced scores (between 55 and 80) were comfort around resting, plumage cleanliness and dust sheet test. Acceptable scores (between 20 and 55) were thermal comfort, stocking density, absence of injuries, footpad dermatitis and hock burn; and unacceptable scores (below 20) were lameness and qualitative behavioral assessment. The median percentage of mortality and culled birds were $5.2 \%$ and $0.6 \%$, respectively. This study provides useful information to select priorities of action on assessed farms and may contribute for setting up legal standards and guiding decisions related to animal welfare issues in Brazil.

\section{INTRODUCTION}

Brazil is the third broiler chicken meat producer in the world, and the South is the main production region (ABPA, 2014). Simultaneous to the development of the Brazilian poultry industry, concerns for the welfare of the chickens have become more evident. In many European countries, citizens have already demonstrated concerns about farm animal welfare standards worldwide, resulting in the development of regulations, certification schemes and assessment protocols for animal welfare. For example, the report of the Scientific Committee on Animal Health and Animal Welfare (SCAHAW, 2000) presented several animal- and environmental-based problems related to fast growth rate chicken strains reared in commercial settings. This report promoted the development of the European Directive 2007/43 (EC, 2007), which was the first regulation to limit stocking density in broiler chicken production in European countries, and also linked maximum densities to outputs, such as mortality and contact dermatitis. Additionally, certification schemes have been developed to ensure compliance with minimal or higher welfare standards in European Union (EU) and third countries. As result, there are approximately 67 animal welfare certification protocols in EU (Areté, 2010). Considering the assessment protocols, the Welfare Quality ${ }^{\circledR}$ (2009), developed by the EU, proposes four main principles of animal welfare: good feeding, good housing, good health, and appropriate behavior. It includes animal-based measures, in addition to farm 
resources and management practices evaluation, which may provide a more comprehensive welfare assessment (Rushen et al., 2011) and has become a trend worldwide (Butterworth, 2013).

The major welfare problems resulting from the current intensive system of poultry production linked to genetic selection are leg disorders, footpad dermatitis, ascites, and sudden death syndrome (EFSA, 2010). The incidence of these diseases vary with animal age, genetic strain and rearing conditions, and has been fully described in international scientific reports (SCAHAW, 2000; EFSA, 2010; EFSA, 2012). Leg disorder prevalence has been reported as between 9\% to 33\% (Sanotra et al., 2003, Knowles et al., 2008) and footpad dermatitis between $22 \%$ and $79 \%$ (Sanotra et al., 2003; Allain et al., 2009; Gouveia et al., 2009). Ascites prevalence was reported as $4.7 \%$ (Maxwell \& Robertson, 1996) and sudden death was 3\% (Maxwell \& Robertson, 1997), and are the main causes of death in broiler chickens (SCAHAW, 2000; Kalmar et al., 2013).

According to Webster (2013), it is time to assess general welfare in order to identify specific problems and to stablish actions to address them. Commercial scale assessment and research on broiler chicken welfare are important tools to provide information about real rearing conditions, and they can help producers to make evidenced-based decisions and to anticipate their impacts (Dawkins, 2012). Welfare assessment has also been an important tool to develop scientific-based recommendations (OIE, 2014) and there is a perspective to include animal-based indicators to support animal welfare regulation in $E U$ (EC, 2012). As a consequence, more effective standards would be developed, since maximum levels for contact dermatitis, for example, could be cited instead of regulations for facility characteristics.

In Brazil, most studies have focused on environmental and managing impacts on animal welfare (Garcia et al., 2010; Menezes et al., 2010; Martins et al., 2013; Carvalho et al., 2014; Lima et al., 2014). However, scientific literature on broiler chicken welfare assessment is scarce in that country, and few studies have been published (Sans et al, 2014; Souza et al, 2015). Thus, this study aimed at assessing broiler chicken welfare on industrial farms in the State of Rio Grande do Sul, Southern Brazil, using the Welfare Quality ${ }^{\circledR}$ assessment protocol for poultry, to provide directly applicable scientific information.

\section{MATERIAL AND METHODS}

\section{Birds and facilities}

Eleven industrial broiler farms were randomly selected from one slaughterhouse, between October $3^{\text {rd }}$ and $14^{\text {th }}, 2011$, considering those keeping chickens within one to five days prior to slaughter. All farms visited, as well as the slaughter house, were located in the region of Passo Fundo, State of Rio Grande do Sul, Southern Brazil, and operated in an integrated system within the same company. Passo Fundo, according to Köppens climate classification, is humid subtropical, without dry season and with hot summer ( $\mathrm{Cfa})$, with an average temperature of $17.7^{\circ} \mathrm{C}$, air humidity of $69 \%$ and maximum precipitation of $167 \mathrm{~mm}$ in October (EMBRAPA, 2006; Alvares et al., 2013). All farms were conventional open-sided houses, with wire mesh sides covered with curtains, and were equipped with nipple drinkers and automatic $(n=9)$ or manual feeders $(n=2)$ (Figure 1, Table 1). Birds were male Cobb $500^{\circledR}$, and were exposed to a total maximum light period of 16 h composed of natural daylight and extra artificial lighting (5 lux). All farms used deep wood-shavings litter; one farm had concrete flooring and ten had earth floor. One housing unit was randomly selected on farms with more than one shed.

Table 1 - Characteristics of poultry houses assessed using the Welfare Quality ${ }^{\circledR}$ protocol, Rio Grande do Sul State, Brazil.

\begin{tabular}{ll}
\hline & Median $(\min -\max )$ \\
\hline Poultry house area $\left(\mathrm{m}^{2}\right)$ & $1,200(600-1,820)$ \\
Number of birds/ poultry house & $13,550(6,500-19,939)$ \\
$\begin{array}{l}\text { Number of birds/ poultry house during } \\
\text { assessment }\end{array}$ & $12,928(6,216-18,527)$ \\
Age of birds during assessment (d) & $40(35-44)$ \\
Age of birds at slaughter (d) & $42(38-45)$ \\
Live weight during assessment (g) & $2,600(2,160-2,960)$ \\
Stocking density $\left(\mathrm{kg} / \mathrm{m}^{2}\right)$ & $28.5(22.4-31.3)$ \\
Stocking density $\left(\mathrm{birds} / \mathrm{m}^{2}\right)$ & $10.5(10.2-11.7)$ \\
\hline
\end{tabular}

\section{Description of the protocol assessment}

One experienced professional on poultry production, who underwent formal theoretical-practical training on the Welfare Quality ${ }^{\circledR}$ protocol, performed all farm assessment. One farm was assessed by day, using the Welfare Quality ${ }^{\circledR}$ protocol (2009), which comprises measures and criteria for each one of the four welfare principles (Tables 2 and 3). Breast blister assessment was adapted, considering any injury observed on breast, additionally to the visual scale proposed by the protocol. Birds were sampled randomly on farm using catching circles and the locations of measures were evenly distributed throughout the house. 


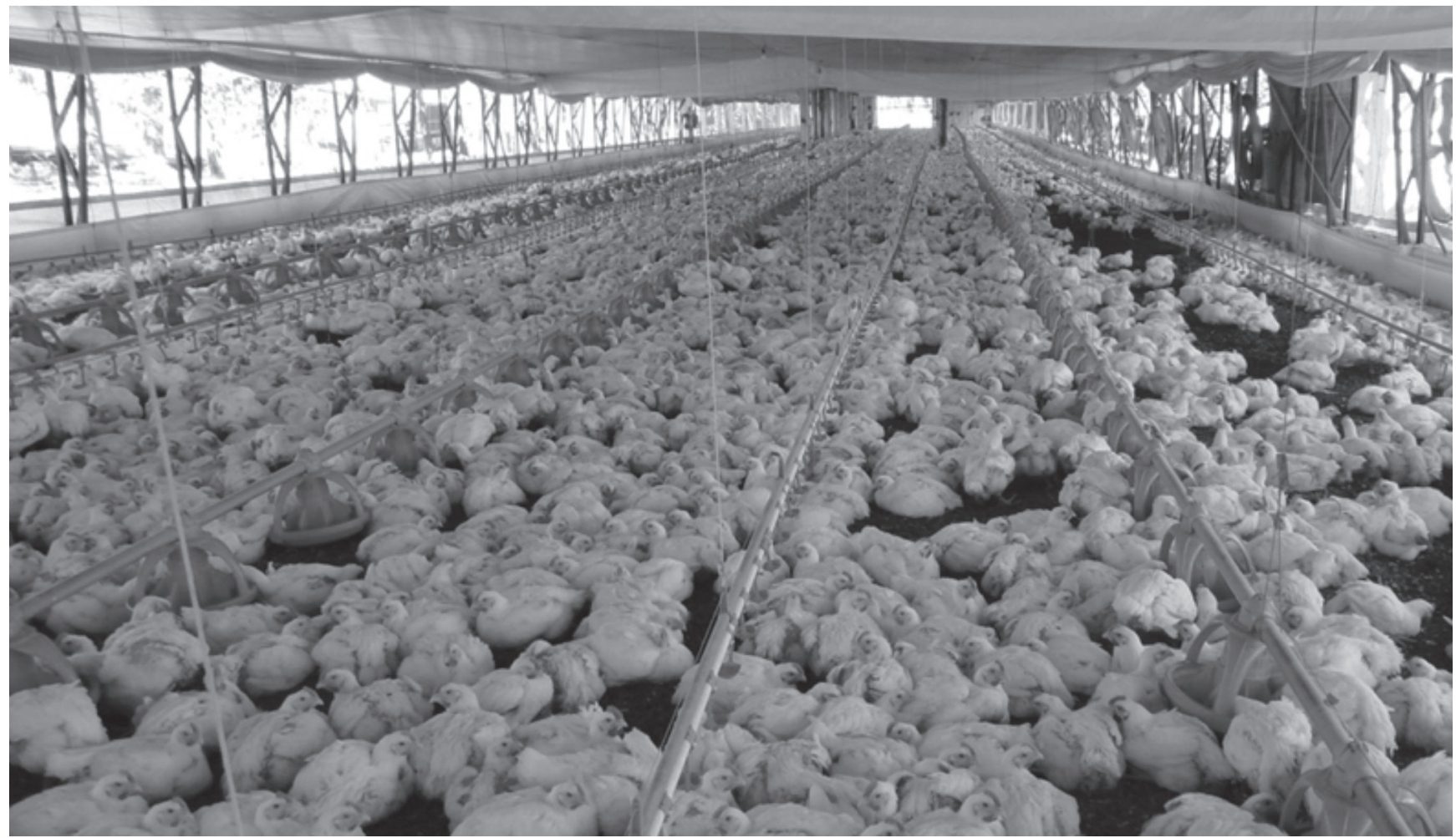

Figure1 - Internal view of a broiler chicken farm in the State of Rio Grande do Sul, Southern Brazil, assessed using the Welfare Quality ${ }^{\circledast}$ protocol.

Table 2 - Welfare Quality ${ }^{\circledR}$ protocol principles, criteria and measures

\begin{tabular}{lll}
\hline Principles & Criteria & Measures \\
\hline Good feeding & Absence of prolonged thirst & Drinker space \\
& Absence of prolonged hunger & Emaciation \\
\hline Good housing & Comfort around resting & Plumage cleanliness, litter quality, dust sheet test \\
& Thermal comfort & Panting and/or huddling \\
Good health & Ease of movement & Stocking density \\
& Absence of injuries & Lameness, footpad dermatitis, hock burn, breast blister \\
& Absence of disease & On-farm mortality, culls on farm, abscesses, ascites \\
Appropriate behavior & Good human-animal relationship & This criterion is not applied, according to the Welfare Quality ${ }^{\circledR}$ protocol \\
& Positive emotional state & Touch test \\
& Expression of social behaviors & Qualitative behavioral assessment (QBA) \\
\hline & Expression of other behaviors & As yet no measure is developed for this criterion \\
\hline
\end{tabular}

\section{Scores calculation and statistics}

Data were transformed into scores that ranged from zero to 100 , with 100 being the best, as described by the Welfare Quality ${ }^{\circledR}$ protocol (2009). Scores were classified as excellent when higher than 80 , enhanced when between 55 and 80, acceptable between 20 and 55 , and not classified when bellow 20. Nine of the 11 flocks were also assessed at slaughter and the measures collected were hock burns, footpad dermatitis and breast blister. Condemnation data from slaughterhouse are presented as percentages. Descriptive statistics was used on data analysis. Correlations between measures were calculated using the Pearson correlation coefficient and were considered moderate if $0.30 \leq r$ $<0.60$ and strong if $0.60 \leq r<0.90$, as described by Callegari-Jacques (2003). Correlations were tested for good housing and absence of injuries, litter quality and plumage cleanliness, litter quality and stocking density, plumage cleanliness and dust sheet test, dust sheet test and thermal comfort, thermal comfort and stocking density, lameness and hock burn, lameness and footpad dermatitis, culls on farm and absence of injuries, hock burn and footpad dermatitis. 
Table 3 - Method of analysis, according to the Welfare Quality ${ }^{\circledR}$ protocol for poultry assessment

\begin{tabular}{|c|c|c|}
\hline Measure & Method & Sampling per farm \\
\hline Drinker space ${ }^{1}$ & Bird: nipple ratio calculation & - \\
\hline Emaciation ${ }^{2}$ & $\%$ of carcass condemnation & - \\
\hline Plumage cleanliness ${ }^{1}$ & Visual inspection, comparing with a 4 points scale & 100 birds \\
\hline Litter quality ${ }^{1}$ & Visual inspection, considering the worst on at least $15 \%$ of locations & Six points \\
\hline Dust sheet test ${ }^{1}$ & $\begin{array}{l}\text { A black A4 paper was placed above bird height on a horizontal surface when first entering the poultry } \\
\text { house. Visual assessment of dust was performed at the end of farm assessment, by passing the finger } \\
\text { on the paper to get an impression of the amount of dust on the paper, comparing with a } 3 \text { points scale. }\end{array}$ & 1 point \\
\hline Panting and/or huddling ${ }^{1}$ & Visual inspection of 100 birds in 5 different locations inside poultry house. & 500 birds \\
\hline Stocking density ${ }^{1}$ & Calculation of $\mathrm{kg} / \mathrm{m}^{2}$ & - \\
\hline Lameness $^{1}$ & Visual inspection of walking ability using a 5 points scale, where 5 is unable to walk & 150 birds \\
\hline Footpad dermatitis ${ }^{1,2}$ & Visual inspection, comparing with a 5 points scale & 100 birds \\
\hline Hock burn ${ }^{1,2}$ & Visual inspection, comparing with a 5 points scale & 100 birds \\
\hline Breast blister ${ }^{1,2}$ & Visual inspection for the presence of injuries & 100 birds \\
\hline On farm mortality $(\%)^{1}$ & $\%$ of mortality calculation & - \\
\hline Culls on farm (\%) ${ }^{1}$ & $\%$ of culling calculation & - \\
\hline Abscesses $(\%)^{2}$ & $\%$ of carcass condemnation & - \\
\hline Ascites $(\%)^{2}$ & $\%$ of carcass condemnation & - \\
\hline Touch test ${ }^{1}$ & Attempt to touch birds in 21 samples/farm, recording the number of birds within arm's length at each trial & - \\
\hline $\begin{array}{l}\text { Qualitative behavioral } \\
\text { assessment (QBA) }{ }^{1}\end{array}$ & $\begin{array}{l}\text { Visual observation of birds for } 10 \text { minutes, recording the level of } 23 \text { emotional descriptors on a scale that } \\
\text { ranged from } 0 \mathrm{~mm} \text { (absence of expression) and } 125 \mathrm{~mm} \text { (maximum expression) }\end{array}$ & - \\
\hline
\end{tabular}

'on farm; ${ }^{2}$ at the slaughterhouse

\section{Results and discussion}

The median (min/max) scores are given in Figure 2. The median frequency of emaciated birds in the criterion of absence of prolonged hunger is presented on Table 4. Lower percentages, of $0.03 \%$ and $0.02 \%$, were observed by Souza et al. (2015) on similar housing conditions, probably due to the practice of culling emaciated birds throughout the rearing process. The absence of prolonged hunger score in other studies were 78.8 and 98.0; and absence of prolonged thirst ranged from 70.5 to 80.0 (Welfare Quality ${ }^{\circledR}$, 2011; Souza et al., 2015). Similar high scores for these criteria were observed in the present study (Figure 2), which were classified as excellent, suggesting that access to food and water was adequate in most cases.

Table 4 - Animal-based measures of 11 broiler chicken farms assessed using the Welfare Quality ${ }^{\circledR}$ protocol, State of Rio Grande do Sul, Brazil, October, 2011.

\begin{tabular}{|c|c|c|c|}
\hline Measure & Median & $\begin{array}{l}\text { Minimum } \\
\text { value }\end{array}$ & $\begin{array}{c}\text { Maximum } \\
\text { value }\end{array}$ \\
\hline Emaciation $(\%)^{2}$ & 0.13 & 0.03 & 0.66 \\
\hline Culls on farm $(\%)^{1}$ & 0.6 & 0.2 & 1.7 \\
\hline On farm mortality (\%) ${ }^{1}$ & 5.2 & 2.9 & 6.9 \\
\hline Culls: mortality ratio $(\%)^{1}$ & 11.0 & 5.0 & 41.0 \\
\hline Abscesses $(\%)^{2}$ & 0.03 & 0.01 & 0.05 \\
\hline Ascites $(\%)^{2}$ & 0.17 & 0.00 & 0.54 \\
\hline 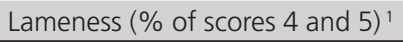 & 14.0 & 4.0 & 27.0 \\
\hline
\end{tabular}

'on farm; ${ }^{2}$ at the slaughterhouse

Plumage cleanliness, which presented enhanced scores, was difficult to measure due to poor feathering on the breast area of the birds. Litter was generally in good visual condition in all farms assessed with small wet and compacted areas, usually under the drinkers. The observed litter quality may be a consequence of low stocking density rates (SCAHAW, 2000) and the presence of natural light inside poultry houses (Bailie et al., 2013). There was a positive correlation of 0.66 between litter quality and plumage cleanliness, which agrees with Berg (2004), who states that plumage cleanliness can also reflect litter condition. Dust sheet test enhanced median score suggests that the concentration of dust was not high; thus, dust did not seem a critical welfare issue on studied farms (Figure 2).

The median score for thermal comfort was classified as acceptable, but the lower limit was close to the unacceptable score (Figure 2). This was a consequence of the high number of birds panting in at least one of the five observed locations inside each poultry house. Despite the fact that houses were open-sided and the use of extra fans, the ventilation system did not appear to be always effective to mitigate the heat stress of the birds. However, the use of totally enclosed poultry barns does not seem to be an efficient way to solve the problem of heat stress in broiler chicken production, as there is a trend to increase the stocking density on these units. According to the EFSA (2012), the risk of heat stress is increased by higher stocking densities and by the genetic strain. Modern fast-growing broiler chickens have difficulties in coping with heat stress, and slow-growing strains are more resistant to hot 


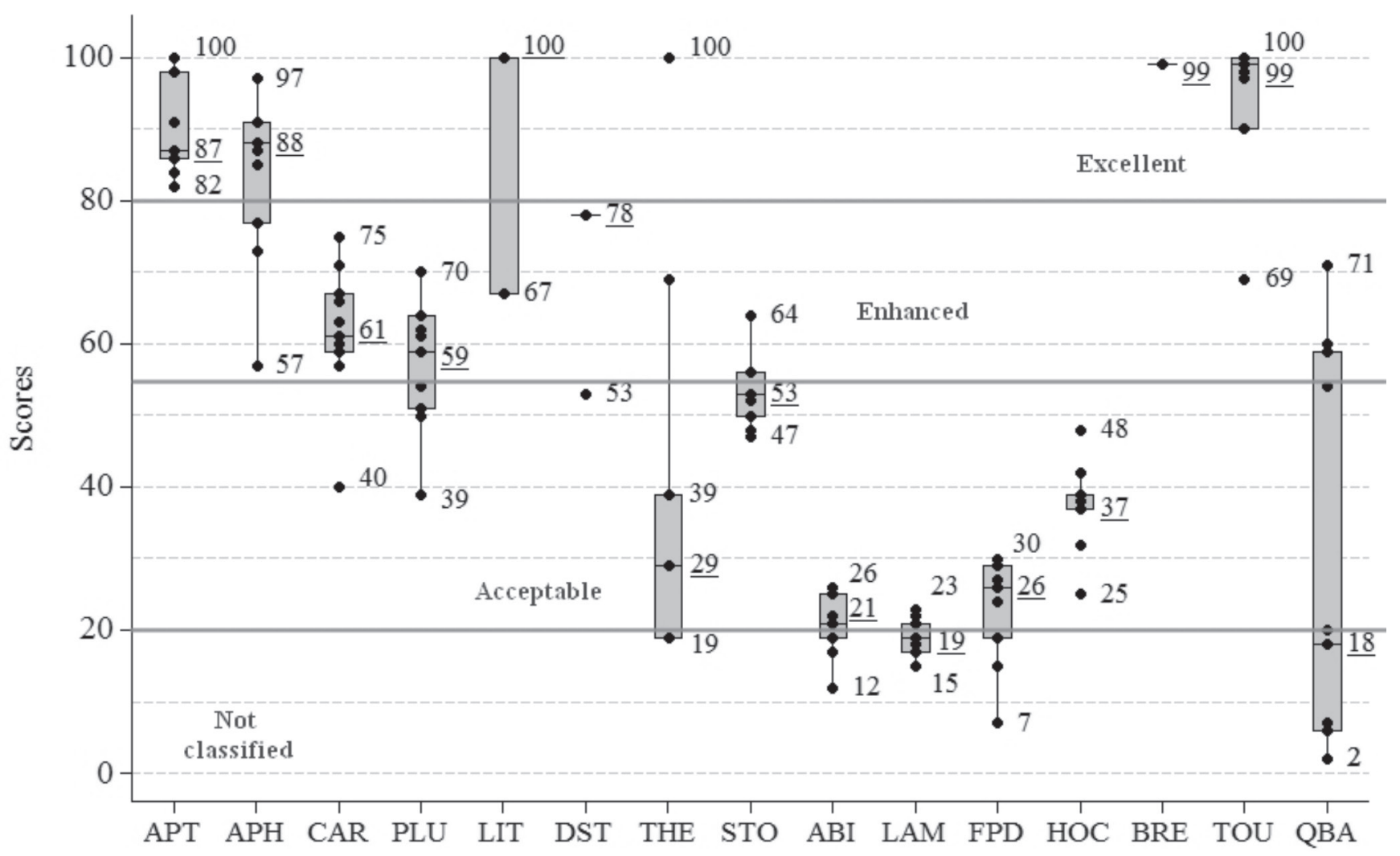

Welfare Quality® protocol criteria and measures

Figure 2 - Scores of 11 broiler chicken farms assessed using the Welfare Quality ${ }^{\circledR}$ protocol, State of Rio Grande do Sul, Brazil, October 2011, underlined data refers to median scores. Continuous lines refer to limits of categories 'excellent', 'enhanced', 'acceptable' and 'not classified'. APT, absence of prolonged thirst; APH, absence of prolonged hunger; CAR, comfort around resting; PLU, plumage cleanliness; LIT, litter quality; DST, dust sheet test; THE, thermal comfort; STO, stocking density; ABI, absence of injuries; LAM, lameness; FPD, footpad dermatitis; HOC, hock burn; BRE, breast blister; TOU, touch test; QBA, qualitative behavioral assessment.

climates (EFSA, 2010). This was corroborated by Sans et al. (2014), which presented score 100 for thermal comfort criterion in free-range Label Rouge broiler chicken farms as result of absence of panting during the assessment using the Welfare Quality ${ }^{\circledR}$ protocol. Thus, heat stress seems to be a critical welfare problem and ought to be addressed in order to improve broiler welfare at the assessed farms.

Stocking density (Table 1) was lower than the maximum stocking densities recommended in existing regulations: $30 \mathrm{~kg} / \mathrm{m}^{2}$ (Switzerland, 2011), $38 \mathrm{~kg} / \mathrm{m}^{2}$ (New Zealand, 2012), and $34 \mathrm{~kg} / \mathrm{m}^{2}$ to $42 \mathrm{~kg} / \mathrm{m}^{2}$ (EC, 2007). It was also lower than $42.6 \mathrm{~kg} / \mathrm{m}^{2}$ (Welfare Quality ${ }^{\circledR}$, 2010) and 18.9 birds $/ \mathrm{m}^{2}$ (Tuyttens et al., 2008) observed in totally enclosed broiler houses in the Netherlands and Belgium, respectively. Lower stocking density, as observed in this study, is characteristic of conventional open-sided houses in Brazil (Bracke et al., 2009). Reducing stocking densities far below from those found under commercial conditions has significant beneficial effects on behavioral activities, including disturbance of rest (Buijs et al, 2009). The moderate median score observed for this criterion, classified as acceptable according to the Welfare Quality ${ }^{\circledR}$ protocol, indicates that the birds would benefit from even lower stocking densities.

The absence of injuries criterion includes important broiler welfare problems, such as contact dermatitis and lameness. Assessed farms presented low score in this criterion (Figure 2), similar to other studies whose scores varied from 20 to 36 (Welfare Quality ${ }^{\circledR}, 2011$; Souza et al., 2015). Scores for hock burns and footpad dermatitis in particular were low, indicating these problems as critical on those farms. Combined for all flocks that were assessed, $84.0 \%$ and $43.0 \%$ of the birds showed some level of footpad dermatitis and hock burns, respectively, with a positive correlation of 0.53 between them. Footpad dermatitis prevalence in other studies varied from $55.0 \%$ to $79.0 \%$ (Gouveia et al., 2009; de Jong et al., 2012; Martins et al., 2013), and Berg (2004) estimated a prevalence of $7.0 \%$ to $20.0 \%$ of hock burn in broiler chickens. According to Greene et al. (1985), flocks with a high incidence of footpad dermatitis often also show a high incidence 


\section{Assessment of Broiler Chicken Welfare in Southern Brazil}

of other types of contact dermatitis, such as breast blisters and hock burns. This was partially confirmed in this study, since no breast blister was observed on birds. Many factors have been suggested to cause footpad dermatitis. According to Santos et al. (2002) and Mayne (2005), the factor most likely to have an effect is litter quality; however, this does not seem to be the case in our results due to excellent median score observed. Kjaer et al. (2006) suggest that, because footpad dermatitis has a relative high heritability, it should also be included in genetic selection programs. Considering that the scores for footpad dermatitis were low, those factors should be addressed to benefit the welfare of the birds.

Lameness also appeared to be a considerable welfare problem, presenting an unacceptable score. The observed median percentage of severe lameness (scores 4 and 5; Table 4) was higher than the prevalence of $3.3 \%$ to $6.6 \%$ observed in other studies (Knowles et al., 2008; Welfare Quality ${ }^{\circledR}, 2010$; Souza et al., 2015). The influence of rapid growth can be considered as the main factor for locomotion problems (Dawkins \& Layton, 2012). Besides the inability to walk, there is evidence that severe lameness is associated with pain (Mench, 2004). Thus, our results reinforce the need of immediate action to reduce lameness in fast-growing strains, as those used on assessed farms. According to Katanbaf and Hardiman (2010), more than half of the 50 phenotypic items evaluated on $\mathrm{Cobb}^{\circledR}$ genetic selection includes animal health, welfare and fitness. However, the EFSA (2010) report criticized this information, since the weight of these items on genetic selection is unknown. Thus, items with economic impact may still be more emphasized. Integration between handling and genetics is pointed as an important tool to improve items related to animal production and welfare (Aggrey, 2010; Dawkins \& Layton, 2012), which means that the resolution of broiler chicken welfare problems may go beyond actions carried out by companies on handling procedures.

The absence of disease criterion included the measures of mortality, culls on farm and slaughterhouse condemnations. Total median mortality rate (Table 4) seems coherent with the values of $2.2 \%$ and $5.0 \%$ found by the Welfare Quality ${ }^{\circledR}$ (2010) study. It was not possible to identify the main reasons for total mortality in this work. Bessei (2006) suggests that sudden death syndrome, ascites, leg problems and contact dermatitis, in addition to high growth rate, are the main reasons for mortality in broiler production systems. Culling reasons on the assessed farms were attributed to small birds (emaciated), birds with injuries and lameness. There was great variation in the culls: mortality ratio (Table 4). The percentage of culled birds in proportion to the total mortality was lower than $20 \%$ in eight farms and never higher than 50\%. According to Welfare Quality ${ }^{\circledR}$ protocol, between 20 and $50 \%$ of the total of birds that died should be culled and the ideal situation is when the proportion is higher than $50 \%$. This is recommended considering that high levels of culling can also reflect the best way to prevent animals from suffering when they are sick or injured. However, the ideal situation regarding welfare is when culling is not needed (EFSA, 2010). The results suggest that the percentage of culled birds as a proportion of the total mortality should be higher in the evaluated farms.

Considering the abscess measure, other studies in Brazil presented similar or higher percentages, varying from $0.02 \%$ to $0.09 \%$ ( Jorge, 2008; Coelho, 2010; Souza et al., 2015). According to the Welfare Quality ${ }^{\circledR}$ (2009), the warning percentage for ascites is $0.5 \%$. These results suggest that these diseases were not critical points for animal welfare on assessed farms.

Excellent median score for human-animal relationship (Figure 2), as measured by the touch test, were due to few avoidance reactions towards humans. A high number of avoidance reactions is thought to reflect fear of humans, which is a major negative emotion (Jones, 1996). Our results suggest, therefore, that fear of humans is not a major welfare concern in most of the assessed farms, even though an important artifact of the assessment methodology related to light intensity in the different types of bird houses was noticed. Light intensity plays an important role in animal behavior, since higher intensities may lead to increased bird activity compared with dim lighting (Bessei, 2006). As consequence, behavioral tests results may differ among farms according to lighting program, and this is an important consideration for comparisons of touch test results across different poultry houses. It is desirable to include this parameter in the Welfare Quality ${ }^{\circledR}$ protocol to provide additional information on data analysis. Additionally, lameness may have an important influence on the touch test results, since lame broilers present reduced activity (Weeks et al., 2000), and consequently, be less willing to move.

The unacceptable score for positive emotional criteria, based on qualitative behavior assessment (QBA), suggests high prevalence of negative emotions and low prevalence of emotions characterized as positive. Evidence on poultry feelings are scarce, but behaviors such as running, jumping, eating, resting 
and dust bathing are considered pleasurable activities, where as hunger, thirst, discomfort, pain, frustration and fear are considered unpleasant situations (Appleby et al., 2004). According to Boissy et al. (2007), the absence of signs of pleasure or positive affect may, on its own, be an indication of a state of affective discomfort, and that promoting positive emotions may help in providing animals with a better quality of life. Most commercial broilers are reared under barren environmental conditions with no attractive stimuli (Sanotra \& Weeks, 2004), and our results for emotional state are probably related to this fact. Increasing environmental complexity may positively affect broiler welfare (Bizeray et al., 2002). Additionally, for a more effective use of QBA in Brazil, it is our understanding that descriptors based on local terms of positive and negative emotions must be developed applying a method similar to that used to produce the list of English terms used in the Welfare Quality ${ }^{\circledR}$ protocol (Wemelsfelder et al., 2000).

\section{CONCLUSION}

On the basis of the Welfare Quality ${ }^{\circledR}$ protocol for the assessment of broiler welfare, the low scores indicated that emotional state, presence of injuries and thermal discomfort appear to be the most severe welfare problems on the assessed farms. Scores of the plumage cleanliness and ease of movement present an intermediate challenge. Absence of prolonged thirst, absence of prolonged hunger and good humananimal relationship showed the best results. This study provides useful information to select priorities of action on the assessed farms and may contribute for setting up legal standards and guiding decisions related to animal welfare issues in Brazil.

\section{ACKNOWLEDGEMENTS}

This project was approved by the Animal Use Ethics Committee of the Agricultural Sciences Campus of the Federal University of Paraná, protocol 045/2011. The authors wish to thank the company and the farmers, and three anonymous reviewers that offered valuable comments.

\section{REFERENCES}

ABPA - Associação Brasileira de Proteína Animal. Relatorio anual 2014 [cited 2014 Dec 29]. Available from: http://www.ubabef.com.br/files/ publicacoes/8ca705e70f0cb110ae3aed67d29c8842.pdf.

Aggrey SE. Modification of animals versus modification of the production environment to meet welfare needs. Poultry Science 2010;89(4):852854.
Allain V, Mirabito L, Arnould, C, Colas M, Le Bouquin S, Lupo C, et al. Skin lesions in broiler chickens measured at the slaughterhouse: relationships between lesions and between their prevalence and rearing factors. British Poultry Science 2009;50(4):407-417.

Alvares CA, StapeJL, Sentelhas PC, De Moraes GJL, Sparovek G. Köppen's climate classification map for Brazil. Meteorologische Zeitschrift 2013;22(6):711-728

Appleby MC, Mench JA, Hughes BO. Causes and effects. In: Appleby M, editor. Poultry behaviour and welfare. Davis: World Animal Protection; 2004. p.30-44.

Areté - Research \& Consulting in Economics. Inventory of certification schemes for agricultural products and foodstuffs marketed in the EU Member States. Brussels; 2010 [cited 2014 Sep 10]. Available from: http://ec.europa.eu/agriculture/quality/certification/inventory/ inventory-data-aggregations_en.pdf.

Bailie CL, Ball MEE, O'Connell NE. Influence of the provision of natural light and straw bales on activity levels and leg health in commercial broiler chickens. Animal: International Journal of Animal Bioscience 2013;7:618-626

Berg C. Pododermatitis and hock burn in broiler chickens. In: Weeks CA, Butterworth A, editors. Measuring and auditing broiler welfare. London: CABI Publishing; 2004. p.37-49.

Bessei W. Welfare in broilers: a review. World's Poultry Science Journal 2006;62:455-566

Bizeray D, Estevez I, Leterrier C, Faure JM. Effects of increasing environmental complexity on the physical activity of broiler chickens. Applied Animal Behaviour Science 2002;79:27-41.

Boissy A, Manteuffel G, Jensen MB, Moe RO, Spruijt B, Keeling LJ, et al Assessment of positive emotions in animals to improve their welfare. Physiology and Behaviour2007;92:375-397.

Bracke $\mathrm{M}$, Horne $\mathrm{P}$ van, Fiks T. Welfare of poultry in a global perspective. In: Bracke MBM, editor. Animal welfare in a global perspective. Wageningen: Academic Publishers; 2009. p.88.

Buijs S, Keeling L, Retternbacher S, van Poucke E, Tuyttens FAM. Stocking density effects on broiler welfare: Identifying sensitive ranges for different indicators. Poultry Science 2009;88:1536-1543.

Butterworth A. On-farm broiler welfare assessment and associated training. Brazilian Journal of Poultry Science 2013;15:71-78.

Callegari-Jacques SM. Bioestatística: princípios e aplicações. Porto Alegre: Artmed; 2003.

Carvalho CM, Litz FH, Fernandes EA, Silveira MM, Martins JMS, Fonseca LA, et al. Incidence in broilers fed a sorghum-based diet. Brazilian Journal of Poultry Science 2014;16 (3):291-296.

Coelho LC. Condenações de carcaças de frangos de corte em linha de inspeção federal no norte do Paraná [dissertation]. Londrina (PR): Universidade Estadual de Londrina; 2010.

Dawkins M, Layton R. Breeding for better welfare: genetic goals for broiler chickens and their parents. Animal Welfare 2012;21:147-155.

Dawkins MS, Donnelly CA, Jones TA. Chicken welfare is influenced more by housing conditions than by stocking density. Nature 2004;427(22):342344.

Dawkins MS. Commercial scale research and assessment of poultry welfare. British Poultry Science 2012;53:1-6.

De Jong IC, van Harn J, Gunnink H, Hindle VA, Lourens A. Footpad dermatitis in Dutch broiler flocks: prevalence and factors of influence. Poultry Science 2012;91:1569-74. 


\section{Assessment of Broiler Chicken Welfare in Southern Brazil}

EC - European Commission. Communication from the Commission to the European Parliament on the European Union strategy for the protection and welfare of animals 2012-2015. Brussels; 2012 [cited 2015 Apr 20]. Available from: http://ec.europa.eu/food/animal/welfare/actionplan/ docs/aw_strategy_19012012_en.pdf.

EC - European Commission. Directive 2007/43/EC of 28 June 2007. Laying down minimum rules for the protection of chickens kept for meat production; 2007.

EFSA - European Food Safety Authority. Scientific opinion on the influence of genetic parameters on the welfare and the resistance to stress of commercial broilers. EFSA Journal 2010;8:1-82.

EFSA- European Food Safety Authority. Scientific report updating the EFSA opinions on the welfare of broilers and broiler breeders; 2012 [cited $2016 \mathrm{Fev}$ 01]. Available from: www.efsa.europa.eu/fr/search/doc/295e. pdf.

EMBRAPA - Empresa Brasileira de Pesquisa Agropecuária. Clima de Passo Fundo. Passo Fundo; 2006 [cited 2015 Apr 29]. Available from: http:// www.cnpt.embrapa.br/pesquisa/agromet/pdf/Clima_de_Passo_Fundo. pdf

Garcia RG, Paz ICL, Caldara FR, Nääs IA, Pereira DF, Freitas LW, et al. Effect of the litter material on drinking water quality in broiler production. Brazilian Journal of Poultry Science 2010;12(3):165-169.

Gouveia KG, Martins da Costa P, Vaz-Pires P. Welfare assessment of broilers through examination of haematomas, foot-pad dermatitis, scratches and breast blisters at processing. Animal Welfare 2009;18:43-48.

Greene JA, McCracken RM, Evans, RT. Contact dermatitis of broilers clinical and pathological findings. Avian Pathology 1985;14(1):23-38.

Jones RB. Fear and adaptability in poultry: insights, implications and imperatives. World's Poultry Science Journal 1996;52:131-174.

Jorge PS. Avaliacão de bem-estar durante o pré-abate e abate e condição sanitária de diferentes segmentos da produção avícola [dissertation]. Jaboticabal (SP): Faculdade de Ciencias Agrárias e Veterinárias; 2008.

Kalmar ID, Vanrompay D, Janssens GPJ. Broiler ascites syndrome: Collateral damage from efficient feed to meat conversion. Veterinary Journal 2013;197(2):169-174

Katanbaf MN, Hardiman JW. Primary broiler breeding-Striking a balance between economic and well-being traits. Poultry Science 2010;89(4):822-824.

Kjaer JB, Su G, Nielsen BL, Sørensen P. Food pad dermatitis and hock burn in broiler chickens and degree of inheritance. Poultry Science 2006;85:1342-1348

Knowles TG, Kestin SC, Haslam SM, Brown SN, Green LE, Butterworth $A$, et al. Leg disorders in broiler chickens: prevalence, risk factors and prevention. PloS one 2008;3:e1545

Lima AOK, Nääs IA, Garcia RG, Borille R, Caldara FR. Impact of diferent light sources on roiler rearing environment. Engenharia Agrícola 2014;34(3):428-434

Martins RS, Hötzel M J, Poletto R. Influence of in-house composting of reused litter on litter quality, ammonia volatilisation and incidence of broiler footpad dermatitis. British Poultry Science 2013;54(6):669-676, 2013.

Maxwell MH, Robertson GW. UK survey of broiler ascites and sudden death syndromes in 1993. British Poultry Science 1998;39(2):203-215.

Maxwell MH, Robertson GW. World broiler ascites survey 1996. Poultry International 1997;36(4):16-33.

Mayne RK. A review of the etiology and possible causative factors of footpad dermatitis in growing turkeys and broilers. World's Poultry Science Journal 2005;61(2):256-267.
Mench J. Lameness. In: Weeks CA, Butterworth A, editors. Measuring and auditing broiler welfare. London: CABI Publishing; 2004. p.3-18.

Menezes AG, Nääs IA, Baracho MS. Identification of critical points of thermal. Brazilian Journal of Poultry Science 2010;12(1):21-29.

National Animal Welfare Advisory Committee. Code of welfare 2012 (meat chickens) under section 75 of the Animal Welfare Act 1999. Wellington; 2012 [cited 2015 Feb 01]. Available from: https://www. mpi.govt.nz/document-vault/1441.

OIE - World Organization for Animal Health. Introduction to the recommendations for animal welfare. In: Vallat B, Thiermann A, editors. Terrestrial animal health code. 23rded. World Organization for Animal Health; 2014

Rushen J, Butterworth A, Swanson JC. Farm animal welfare assurance: science and application. Journal of Animal Science 2011;89:12191228.

Sanotra GS, Berg C, Lund JD. A comparison between leg problems in Danish and Swedish broiler production. Animal Welfare 2003;12(4):677-683.

Sanotra GS, Weeks CA. Abnormal Behaviour and Fear. In: Weeks CA, Butterworth $A$, editors. Measuring and auditing broiler welfare. London: CABI Publishing; 2004. p. 71-77.

Sans ECO, Federici JF, Dahlke F, Molento CFM. Avaliação de grau de bemestar de frango de corte tipo caipira pelo Welfare Quality. Revista Brasileira de Ciência Avícola 2014;16:297-306.

Santos RL, Nunes VA, Baião NC. Pododermatite de contato em frangos de corte. Arquivo Brasileiro de Medicina Veterinária e Zootecnia 2002;54(6):655-658

SCAHAW- Scientific Committee on Animal Health and Animal Welfare The welfare of chickens kept for meat production (broilers). 2000 [cited 2014 Nov 30]. Available from: http://ec.europa.eu/food/fs/sc/scah/ out39_en.pdf.

Souza APO, Sans ECO, Müller BR, Molento CFM. Broiler chicken welfare assessment in GLOBALGAP certified and non- certified farms in Brazil. Animal Welfare 2015:24(1):45-54

Switezerland. Animal Welfare Ordinance. 2011 [cited 2015 Fev 02] Available from: http://www.blv.admin.ch/themen/tierschutz/index $\mathrm{html}$ ? lang=en\&download=NHzLpZeg7t, Inp6IONTU042I2Z6In $1 \mathrm{ad} 1 \mathrm{IZn}$ 4Z2qZpnO2Yuq2Z6gpJCFd3t2fmym162epYbg2c_JjKbNoKSn6A--

Tuyttens F, Heyndrickx M, De Boeck M, Moreels A, Van Nuffel A, Van Poucke $E$, et al. Broiler chicken health, welfare and fluctuating asymmetry in organic versus conventional production systems. Livestock Science 2008:113:123-132.

Webster J. International standards for farm animal welfare: science and values. The Veterinary Journal 2013;198:3-4.

Weeks C, Danbury T, Davies H, Hunt P, Kestin S. The behaviour of broiler chickens and its modification by lameness. Applied Animal Behaviour Science 2000;67:111-125.

Welfare Quality ${ }^{\circledR}$. The assessment of animal welfare on broiler farms [Report 18]. Cardiff; 2010.

Welfare Quality®. Welfare Auality scoring system. 2011 [cited 2014 Nov 26]. Available from: http://www1. clermont.inra.fr/wq/index. php?id=farms\#criteria. Accessed: 26 nov 2014.

Welfare Quality®. Welfare Quality assessment protocol for poultry (broilers laying hens). Lelystand: Welfare Quality® Consortium; 2009.

Wemelsfelder F, Hunter EA, Mendl MT, Lawrence AB. The spontaneous qualitative assessment of behavioural expressions in pigs: First explorations of a novel methodology for integrative animal welfare measurement. Applied Animal Behaviour Science 2000;67(3):193-215. 